\title{
Building Capacity for Intercultural Citizenship
}

\author{
Ida Castiglioni' ${ }^{1}$, Milton J. Bennett ${ }^{2}$ \\ ${ }^{1}$ Department of Sociology and Social Research, University of Milano Bicocca, Milano, Italy \\ ${ }^{2}$ Intercultural Development Research Institute, Hillsboro, OR, USA/Milano, Italy \\ Email: ida.castiglioni@unimib.it, milton.bennett@idrinstitute.org
}

How to cite this paper: Castiglioni, I. and Bennett. M.J. (2018) Building Capacity for Intercultural Citizenship. Open Journal of Social Sciences, 6, 229-241. https://doi.org/10.4236/jss.2018.63016

Received: February 20, 2018

Accepted: March 27, 2018

Published: March 30, 2018

Copyright $\odot 2018$ by authors and Scientific Research Publishing Inc. This work is licensed under the Creative Commons Attribution International License (CC BY 4.0).

http://creativecommons.org/licenses/by/4.0/ (c) (i) Open Access

\begin{abstract}
Changing national boundaries, migration and mobility, multinational residence, and the cross-border flow of refugees are challenging traditional views of citizenship. The term "intercultural citizenship" is coined to refer to a definition based more on affiliation with a cultural group than on legal ascription to a nation state. The implications of citizenship based on belonging carry some of the same rights and responsibilities as legal citizenship, but in addition they include 1) conscious identification with chosen groups; 2) acceptance of responsibility for sustaining the commonweal in a variety of ways; 3 ) development of flexible perceptual boundaries that allow for multiple group identifications; and 4) participation in the group coordination of meaning and action that constitutes the maintenance of a living culture. Three major factors in building capacity for intercultural citizenship are explored: 1) capacity for empathy, which involves overcoming the golden rule and its assumption of similarity to embrace the platinum rule and the assumption of difference; 2) capacity for mutual adaptation, which generates virtual third cultures, or forms of communicative intersectionality; and 3) capacity for intercultural ethicality, which demands that judgments be made among viable alternatives revealed by empathic perspective-taking.
\end{abstract}

\section{Keywords}

Citizenship, Identity, Empathy, Ethicality

\section{Introduction}

Citizenship is typically defined as membership in some kind of political entity; recently; of course, those are entities of nations and states (Isin \& Turner 2002; Derek, 2004) [1] [2]. Citizenship usually is defined in terms of rights and responsibilities (Archibugi, 2008; Soysal, 1994) [3] [4]. However, changing national boundaries, migration and mobility, multinational residence, and the 
cross-border flow of refugees are challenging this straightforward assumption. Increased global mobility is creating tensions between nationality in the sense of residency in a nation, and citizenship, in the sense of enjoying the privileges of membership such as voting and other forms of participation. Does one, by virtue of residing in a nation, take on the responsibilities but not necessarily the privileges of membership of that organization, unless one is a citizen, in which case citizenship becomes a kind of a perk-a condition of relative elitism? (Van der Ploeg, 2016; Young, 1989) [5] [6]. Additional confusion of rights and responsibility is created by multiple membership in groups, such as dual national citizenship, or multiple levels of citizenship, for instance of a state, of a canton, of a nation, of a commonwealth or a union. Dual or multiple citizenship is particularly troublesome when political entities of which one is a citizen are in opposition to one another, such as when nations are at war or a state is rebelling against a federal government (Kymlicka, 2001) [7].

This paper will suggest an approach to citizenship in multiple groups that is more of a process than a thing-something we do more than something we have. By de-reifying the concept of citizenship, we can more easily conceive of simultaneously maintaining different kinds of membership in different kinds of groups. And since the feeling of "belongingness" is an important aspect of group membership in general (Stokes-Du Pass \& Fruja, 2016) [8], we will suggest that it also should be an important constituent of a more conscious, or intercultural, citizenship.

\section{A Definition of Intercultural Citizenship}

We maintain the idea of citizenship as referring to a quality of group identification and a degree of civic responsibility (Brewer, 2009) [9]. Building on these more active and less reified qualities, we define intercultural citizenship as the conscious identification with and acceptance of responsibility for participating in one or more cultural boundary conditions that define groups of people who are coordinating meaning and action. The following sections expand this definition, and subsequent sections explore three capacities that are necessary for intercultural citizenship: empathy, virtual third cultures, and ethicality.

\subsection{Conscious Identification}

Conscious identification refers to the idea that intercultural citizenship is not an accidental condition of birth. Instead, this kind of citizenship is chosen, either as a conscious affirmation of a birth condition or as an intentional act of embracing some group other than the default one. Migrants who become naturalized citizens of a host country are of course the primary example of this kind of conscious identification, but the idea could apply to people who acquire a second or third citizenship. It also could apply less formally to people who consider themselves citizens of a larger regional entity, such as Europe, or of a smaller regional entity such as Northern Italy. However, the idea of conscious identification 
should exclude people who acquire a second citizenship when it is only for the purpose of getting an additional passport. In other words, we are restricting the idea of intercultural citizenship to chosen conditions of belongingness, not to the condition of formal legal status.

We can think of membership in both individualistic and collectivist ways. Individual membership means that we feel affiliated with the group; we feel a sense of belongingness. We may feel American, or Italian, or we may not feel Italian but just Milanese, or we may not feel Swiss but feel Italian-Swiss. The groups we affiliate with become part of our cultural identity. At the same time, in a collectivist sense, we are ascribed to membership in groups. We may be ascribed membership to a group with which we do not affiliate. For instance, people might be ascribed to US American culture, whether or they felt belongingness (affiliation) with that national group. The ascription could be based on citizenship (passport identity), or long-term residence, cultural heritage, or some combination of those things. People can be seriously advantaged or disadvantaged by cultural ascription, so the personal stakes are high in trying to negotiate this kind of identity (Kabeer, 2002) [10].

Political entities such as the European Union or the United States could benefit from encouraging multiple feelings of belongingness (affiliation) along with multiple citizenship (ascription). The addition of a Federal level of citizenship to the state level is relatively recent in the US, and expressions of distrust by citizens of states toward "the federal government" are still common (Percy, 2018) [11]. In the terms being used here, some of the US Americans who are attributed membership in the federal entity by virtue of their citizenship in fact do not feel affiliated with it-their affiliation is only for the smaller entity of state or local governance. The discrepancy is more pronounced in the EU, where the long history of individual nation-states impedes affiliation with the larger regional entity. In both cases, the larger entities could benefit from stressing that affiliation with them does not conflict with more local affiliation. Switzerland, with its relatively weak federal structure and strong local structures may be one model of how multiple affiliations can be maintained.

As Kymlicka, (2011) [12] argues, the real challenges to the idea of nation states come from historic internal minorities, not from outside individuals such as immigrants. There's a need for citizenization, a term borrowed from Tully (2001: 25) [13], in contemporary Western democracies counteracting ideas of political community and current citizenship agendas. The process of citizenization in multination states has four relevant indicators: 1) peace and individual security; 2) democracy; 3) individual freedom; 4) inter-group equality. The last indicator is particularly important here as it implies equality between majority and minority groups in society, assessed along economic, political and cultural lines. In other words, the reduction of the historic patterns of cultural marginalization and economic and political oppression is a major lever for the success of this process. While most of these issues are part of world agencies agendas, such 
as the United Nations, it must be noted that countries that have been successful in the internal integration of their "nations" are unable or unwilling to renegotiate rules in order to accommodate migrants to a new form of citizenship, Switzerland being an egregious example of this conduct.

\subsection{Acceptance of Responsibility}

Acceptance of responsibility refers to the conscious recognition of civic responsibility-the familiar idea of the "commonweal" (Ehrlich, 2000) [14]. We reiterate the idea that commitment to the commonweal is an intentional act, and with that commitment comes the responsibility to choose our individual acts in the context of human and physical ecologies (Unesco, 2015) [15]. However, we add the intercultural idea that we can and should feel responsibility for multiple contexts simultaneously - that our actions reverberate with our family, our immediate neighbors, our city, our region, our country, and our more distant neighbors in interconnected nations and regions. With this definition we reject the idea that a collection of selfish actions translates into goodness for the commonweal, but we also are suspicious of the idea that institutions can themselves guarantee the common good. Instead, we are suggesting that a constant attention to the dialectic of self and other is necessary to coordinate action responsibly.

Moreover, we agree with the UNESCO paper on Rethinking Education (2015) [15] that the role of education needs to be re-contextualized and knowledge considered as a common good. "Knowledge" in this case is the body of information, skills, understanding, values, and attitudes acquired through learning. Considering knowledge as a form of collective societal endeavor demands more responsibility than just defining education as a human right. Certainly education is a fundamental right and a public good, but knowledge itself should be considered an integral part of the commonweal. Consequentially education cannot stop at school level but needs to encompass lifelong learning. Non-formal and informal education are not often considered as a common good, but they are essential components of enabling people to participate in life and in the construction of an enlarged concept of citizenship. Also, integrating alternative knowledge systems is necessary in order to strive for more equality and dignity of different parts of societies. Valuing diversity is also valuing different ways of knowing.

\subsection{Modifying Cultural Boundary Conditions}

Cultural boundary conditions are the perceptual distinctions that we necessarily draw between self and others-the construction of alterity (Uchoa Branco \& Lopes de Oliveira, 2018) [16]. As a condition of intercultural citizenship, boundaries must be mutable; the self and other are constantly being re-defined by reconfigurations of the boundary. Thus, one might one minute be a woman and not a man, but the next moment an Italian and not a Greek, and the next a Eu- 
ropean and not an Asian. While these distinctions are stated as binary, it does not mean that the possible boundary conditions are themselves binary. For instance, one might be a man and not a woman while simultaneously being a gay man not a straight man, or, to move up a level of abstraction, to be intersexual and not monosexual. The boundary conditions can be constructed in an infinite number of ways (Bennett \& Castiglioni, 2004) [17], and our affiliation with some combination of them constitutes our "intercultural identity."

\subsection{The Coordination of Meaning and Action}

Edward Hall (1973) [18] wrote in his original work on culture that there is a "silent language" that forms and maintains culture: the coordination of meaning and action in a group. In this view, the term "culture" is a way of referring to the collective communication of some defined group of people. Communication is itself the mutual construction of meaning (Von Glasersfeld, 2003) [19] - a way for people to coordinate intention with interpretation. So, writ large, culture is a particular set of implicit rules for matching intention with interpretation-rules that are more or less shared by people whose group boundary is defined by some critical level of that commonality. The implication of this definition of culture for intercultural citizenship is that culture is not a thing that we have. Rather, culture is something that we $d o$, and each of us can develop a repertoire of doing it in significantly different ways.

\section{Capacities for Intercultural Citizenship}

Intercultural citizenship as defined above demands a kind of perceptual agility in taking perspective and generating alternative experience. There are obviously many impediments to maintaining this kind of consciousness. Here we explore three capacities that have been suggested as central to reducing the impediments and supporting the conscious exercise of belonging.

\subsection{Overcoming the Golden Rule}

According to classic work by M. Bennett $(1979,2013 a)$ [20] [21], a major impediment to maintaining an intercultural identity is our unthinking allegiance to the golden rule: "Do onto others what you would have done onto you", or "treat other people the way you would like to be treated". Something like the golden rule is stated by most major religions. Certainly the golden rule is a good alternative to considering other people as sub-human, with all its attendant horrors. But in modern multicultural times, we also need to ask, "Why would other people want to be treated the way you want to be treated?" The golden rule is based on an assumption of similarity, which holds that it is good and sufficient to attend to the things that make us similar as human beings-things such as our shared need for food, sleep, and entertainment, or more speculative similarities such as common beliefs or values. Because of this assumption we may at best approach others sympathetically, defined as attempting to understand others by 
putting ourselves in their positions-"standing in the other person's shoes" (Bennett, 2013a: 211) [21].

The reason the golden rule is so popular is that it often works-more frequently with people who share a cultural affiliation and particularly with friends. This may be because people choose their friends to be like them (Heine, 2015) [22]. The golden rule is less effective with life partners, probably because we choose those people more on the basis of complementarity (difference) than on symmetry (similarity) (Watzlawick et al., 1967) [23]. For the same reason, the golden rule is not particularly effective at work, since we generally don't choose the people we work with.

In multicultural situations, what happens when we treat others the way we'd like to be treated and they don't respond the way we'd respond? Do we realize our inaccurate assumption of similarity and try a different strategy? Unfortunately we are more likely to employ the lead rule: "treat other people the way they deserve to be treated" (Bennett, 2013a: 210) [21]. How others deserve to be treated depends on our explanation for why they don't respond well to the golden rule. If we think others are unaware of the appropriate response, we may seek to educate them-to explain how our preferred behavior is also the best one for them. If they refuse to be educated in that way, we may shift to the explanation that there is something temporarily wrong with them-a mental and/or hormonal disturbance, for instance. It that case we may therapize them in the sense of exercising patience and support for changing behavior into more appropriate forms. If they still refuse to change, we may assume that they have malevolent intent and that we are therefore justified in controlling their behavior, or even punishing them.

The breakdown of the golden rule has obvious parallels to the way immigrants, refugees, and non-dominant minority groups are often treated by initially well-meaning members of the dominant majority. After receiving lessons in how to assimilate to the dominant culture-that is, how to become a good citizen-and at the expiration of a period of patience for the lessons to sink in, recalcitrant others may reluctantly be consigned to the judiciary or other controlling social institutions. The problem may not be with them, but rather with our expectation that, deep down, they are actually similar to us.

A more interculturally sensitive strategy is the platinum rule: treat other people the way they would like to be treated, or at least be aware of what that is and be prepared to explain why it is not being done (Bennett, 2013a: 230) [21]. For example, people might wish to dress in a particular way that shows their commitment to a religious principle, but they may be trying to operate in a society that has decided to have public spaces in which that dress is not allowed. All societies operate by a dominant group of people deciding what is acceptable and what is not acceptable. Either formally or informally, such rules will be imposed on everyone in the society. The question is: how can that be done respectfully in the face of disagreement? In other words: how can we avoid applying the 
lead rule-“you stupid people don't understand how important this is!"-in favor of using the platinum rule-"We recognize how this is an important thing to you, and here is how we-together-can try to come up with a solution that is respectful to you and your custom, but nevertheless operates within this social context". The platinum rule is based on the idea that people are different and that difference is good, but recognizes that action must still be coordinated in some way.

The strategy for understanding others associated with the platinum rule is empathy. Empathy demands that we try to take other people's perspectives, not that we merely place ourselves in their positions. For this to occur, we must consider how the others are potentially different from ourselves. In other words, we need to attribute equal humanity to the other, and go through the trouble of trying to understand how others might be perceiving and experiencing reality differently from us. While this empathy has a better chance than sympathy of being accurate in cross-cultural situations, its accuracy is not the main point. Empathy is intrinsically valuable as an acknowledgement of potential differences between ourselves and others. Respectfully acknowledging difference in preference or belief (but not necessarily agreeing to act according to that difference) is the foundation of attributing equal humanity to others (Hofstadter \& Dennett, 1982) [24]. Intercultural citizenship demands this respect for difference as a necessary starting point for coordinating meaning and action in multicultural societies.

\subsection{Mutual Adaptation (Virtual Third Cultures)}

One of the key issues of citizenship in multicultural groups is the thorny question of who adapts to whom. The traditional answer has been "When in Rome do as Romans do". We could now say that "everywhere is Rome" as a reference to cultural mixing. Assuming that a culturally mixed group still needs to act in some coordinated way (to accomplish a task, or to survive as a society), it must decide who in the group will adapt to what standards. So who determines the form of adaptation? Are they the majority? The dominant group who make the rules? The people who've been around the longest? The people who've been most successful? The people who exercise the most immediate power? This question demands consideration far beyond simple behavioral checklists or equations of cultural difference that populate superficial intercultural training. The deeper issue is how we can live together with different and possibly competing values, while maintaining a coordination of meaning and action that allows our group to survive and thrive. The question cannot be, "whose values will prevail?" We are now too interconnected across different value systems to indulge in that exercise in ethnocentrism. The question now must be, "how can we incorporate value differences into the fabric of our societies?"

Research on diversity in groups indicates that the mere existence of cultural diversity does not represent any particular value to that group; it gives the group 
access to the cultural difference, but it does not make it an asset (Adler \& Gundersen, 2008; Moss-Kanter, 1997) [25] [26]. Groups need to do something intentionally to turn the access into an asset. By extension, we could say that multiculturality in itself does not confer value to a society. Rather, it represents a potential value, depending on how cultural adaptation is handled. If cultural difference is suppressed in favor of one-way assimilation to the host culture, the potential value is unrealized. But if groups adapt rather than assimilate, the potential is more likely to be realized.

Adaptation differs from assimilation in that the former is additive rather than substitutive (Bennett, 2013) [27]. Where the goal of assimilation is to establish the host culture's dominant worldview, the goal of adaptation is to add the host worldview to the repertoire of possible experience. In the case of one-way adaptation, members of a cultural group entering an established society would become bi-cultural in their native and the host cultures. John Berry (2016) [28] refers to this position as integration. One-way adaptation, or integration, preserves the potential value of cultural diversity in a multicultural society, but it doesn't necessarily create the conditions for the potential to be realized. Instead, added value is realized when both members of the entering culture try to adapt to the host culture and members of the host culture attempt reciprocally to adapt to the others-mutual adaptation (Berry, 2005; Kim, 2001) [29] [30].

Mutual adaptation generates third culture, which can be defined as a kind of communicative intersectional space. The term "intersectionality" has been used to refer to the co-ontological and inextricably intertwined aspects of personal and social identity that permeate every social interaction (Johnston Conover, 2009; hooks, 2013; Yuval-Davis, 2006) [31] [32] [33]. In the case of communicative intersectional space, each participant's attempt to coordinate meaning and action across a cultural boundary takes into account the other participant's differing perspective-a relationship is formed that becomes part of the worldview of each participant. Joint attention to the other creates an intercultural form of what Martin Buber (1958) [34] called the I-thou relationship-one in which the humanity of each participant is affirmed. In that condition of mutual empathy, attempts to coordinate action are more likely to result in a mutually acceptable solution.

Third culture is a virtual condition-it comes into existence when culturally different participants are engaging in mutual adaptation. A society or an organization does not itself become a third culture; rather, the organization becomes more competent in supporting third culture positions that flicker in and out of existence. And it is from these third cultures that added value is realized in an organization or society. The value does not come from different cultures just being around; it comes from members of those cultures attempting to adapt to each other, to engage in mutual empathy.

There are several profound implications of third culture for intercultural citizenship. On a small scale, it implies that diversity efforts focusing on the re- 
cruitment of underrepresented people into organizations are not inherently valuable. Such efforts need to be accompanied by mechanisms that allow the diverse views carried by people with different worldviews to interact with others in respectful ways. On a societal level, cultural diversity driven by migrant or refugee mobility is likely to be troublesome unless it becomes part of a mutual adaptation in the society; that is, newcomers adapt to the host culture, but the host culture reciprocally adapts to the newcomers. In both cases, the establishment of a climate of respect for diversity generates the conditions for mutual adaptation, and the resulting third-culture solutions can add value to the activity of the group.

\subsection{Intercultural Ethicality}

People used to think (and still do in some quarters) there was a single truth, that one's own group had it, and that therefore one's own group was superior and justified in dominating others in the name of the truth. In these post-colonial and (more or less) post-imperialistic days, it is more common to believe that world domination in the name of a single truth is unsustainable and unethical. Yet the alternative is not a simple matter of saying, "Well, you have your truth, I have mine, so, whatever..." In fact, we need to coordinate ourselves to survive. So the question is, "how do we coordinate ourselves in non-absolutist ways-ways that preserve diversity but also generate common purpose?"

The problem is that many people want to respect (or at least tolerate) cultural relativism, but they also want to reject moral relativism. In other words, they want to accept the relativist idea that humans have viable alternative ways of surviving and thriving in their environments, but they do not want to accept the concomitant idea that humans might have viable alternative ideas of truth and goodness. This uneasy dichotomy can be maintained from afar, but it deteriorates quickly when absolutist ideas of truth and goodness are imposed in multicultural societies and propagate through the interconnected global village.

Obviously, when we say we want to appreciate cultural difference and engage in mutual adaptation, we need to use empathy and the platinum rule. But what happens when inevitable conflict rises? How can we act definitively in ways that are respectful of differing views? In conflict situations that demand action, we usually have not developed any alternative to the imposition of absolute standards. The absolute standards might be secular principles that are seen as the ultimate of human development, such as human rights or free speech, or they might be sacred values that are taken to be universal - God's word in one form or another. When standards are imposed in these terms, they are inherently disrespectful of the difference involved in the conflict. Yet they continue to be invoked because too often the only alternative is a kind of extreme relativism in which no definitive action is possible- "whatever." Societies and organizations cannot run on the basis of "whatever". But if the only alternative to "whatever" is the imposition of universal values, societies and organizations will be unable to 
coordinate meaning and action towards common purpose.

William Perry's (1969) [35] scheme of cognitive and ethical development, especially with Lee Knefelkamp's additions, offers a direction towards addressing this conundrum. In her introduction to the revised edition, Knefelkamp (1999) [36] makes the case that the Perry Scheme, despite having been devised in the context of male Harvard University students, is not biased toward men's ways of knowing compared to other popular ethical schemes such as that of Kohlberg (1981) (Gilligan, 2008) [37] [38]. The Perry Scheme is developmental in the sense that it assumes that issues of earlier stages need to be reconciled to allow movement to later stages.

In the initial stages of the Perry developmental sequence, seeking truth, we assume an absolute right and wrong that is given by an authority-frequently parents, or church figures. This is of course the familiar condition of dualism that drives most naïve systems of morality. As we encounter greater complexity such as the differing truths presented in higher education, we may develop multiplicity-the "whatever" position. In multiplicity we have lost absolute truth but haven't yet formed an alternative. As long as we are seeking truth, we may oscillate between absolutism and multiplicity, where "whatever" periodically gives way to following a new guru or uncovering a new conspiracy. Breaking out of these oscillations requires an epistemological development-a paradigm shift that allows perception to be processed in a different way. That shift is from an absolutist position to a relativist position. In the relativist position, which Knefelkamp calls contextual relativism, the assumed goodness of something is necessarily seen in context. We come to see that values that we might find good, such as freedom of expression, are good in the context of our cultural affiliations. While we might believe that human rights are the acme of human development, others who are operating with different cultural affiliations may believe that the acme is following God's word. We do not have to say which one of those is true, we just need to recognize that they each exist in a context and are consequential to the people in that context. This is similar to the idea of empathy discussed earlier.

Perry's last stages of commitment in relativism demand yet another paradigm shift, to constructivism (M. Bennett, 2013) [27]. The essence of that epistemological position is the same one underlying communicative intersectionality and the co-ontogenic construction of third cultures. It is an answer to the question, "how can we act in definitive ways that coordinate meaning and action and that support commonality of purpose in a way that is respectful to disagreement"? Perry suggests that to do that, we need to commit ourselves to an action in the face of viable alternatives. As we encounter multiple perspectives, we encounter and develop multiple commitments to values. We construct a way of being in the world that respects the viable alternative of the other, and yet moves forward into our own commitment. Assuming it is a mutual adaptation, others are also moving toward their commitment, but with equal respect for the viability of our 
commitment. The result is the third culture that ideally incorporates value from both positions in a synergistic way (Bennett, 2013; Adler, 1980; Casmir, 1993) [27] [39] [40].

Although the ideal is third culture-and in many circumstances that is a very achievable goal-some circumstances may preclude the mutual adaptation from occurring. Usually this happens when one party to a disagreement thinks they are absolutely right based on an absolute truth, and the other party is absolutely wrong. In other words, one side (or maybe both sides) denies the viability of the other position. Action taken in this condition is intrinsically disrespectful. But assuming the disagreement is consequential, judgments must be made and action taken, and in such situations inaction constitutes action. So whatever is not a viable option.

The alternative process suggested by Perry and Knefelkamp (1999) [33] is based on recognizing contextual goodness. Religious zealots who are chopping off the heads of infidels think they are doing a good thing. Why? Before a consortium of people in the world mount a campaign to stop the zealots from doing that, we need to understand why people believe that beheading infidels is good... not why the action is an evil thing being done by animals, but why it is a good thing, from their perspective, being done by equally complex human beings. Once we understand that we can make a commitment. There are many commitments that might involve the use of forceful imposition, such as military intervention in genocides. But if we try to stop people from doing something before we understand why they think it is a good thing, or if we deny their equal humanity, then we are engaging in the same kind of hegemonic, colonialist, imperialistic imposition we have always engaged in; we impose our truth because we have the power to do so.

The alternative that supports intercultural citizenship is to acknowledge the viability of the other's position. In the case of beheading, the world has survived under religious zealots for a lot longer than it has been run by post-enlightenment secularists, so it is at least a historically viable position. But does that mean that we should agree to the world continuing to be that way? Not necessarily. By being knowledgeable and respectful of the alternative context before we try to change it, we have exercised our responsibility as intercultural citizens.

\section{References}

[1] Isin, E.F. and Turner, B.S., Eds. (2002) Handbook of Citizenship Studies. Sage, Thousand Oaks.

[2] Derek, H. (2004) A Brief History of Citizenship. NYU Press, New York.

[3] Archibugi, D. (2008) The Global Commonwealth of Citizens. Toward Cosmopolitan Democracy. Princeton University Press, Princeton.

[4] Soysal, Y. (1994) Limits of Citizenship. Migrants and Postnational Membership in Europe. University of Chicago Press, Chicago.

[5] Van der Ploeg, P.A. (2016) Dewey versus "Dewey" on Democracy and Education. Education, Citizenship and Social Justice, 11, 145-159. 
https://doi.org/10.1177/1746197916648283

[6] Young, I.M. (1989) Polity and Group Difference: A Critique of the Ideal of Universal Citizenship. Ethics, 99, 250-274. https://doi.org/10.1086/293065

[7] Kymlicka, W. (2001) Politics in the Vernacular: Nationalism, Multiculturalism and Citizenship. Oxford University Press, New York. https://doi.org/10.1093/0199240981.001.0001

[8] Stokes-DuPass, N. and Fruja, R. (2016) Citizenship, Belonging, and Nation-States in the Twenty-First Century. Palgrave Macmillan US.

[9] Brewer, M. (2009) Social Identity and Citizenship in a Pluralistic Society. In: Borgida, E., Federico, C.M. and Sullivan, J.L., Eds., The Political Psychology of Democratic Citizenship, Oxford University Press, New York. https://doi.org/10.1093/acprof:oso/9780195335453.003.0007

[10] Kabeer, N. (2002) Citizenship and the Boundaries of the Acknowledged Community: Identity, Affiliation and Exclusion. IDS Working Paper 171. Institute of Development Studies, Brighton, 1-40.

[11] Percy, J. (2018) Fear of the Federal Government in the Ranchlands of Oregon. New York Times Magazine, Jan. 18, 2018.

[12] Kymlicka, W. (2011) Multicultural Citizenship within Multination States. Ethnicities, 11, 281-301. https://doi.org/10.1177/1468796811407813

[13] Tully, J. (2001) Introduction. In: Gagnon, A. and Tully, J., Eds., Multinational Democracies, Cambridge University Press, Cambridge, 1-33. https://doi.org/10.1017/CBO9780511521577.003

[14] Ehrilch, T. (2000) Civic Responsibility and Higher Education. The American Council on Education and the Oryx Press, Westport.

[15] UNESCO (2015) Rethinking Education. Towards a Global Common Good? https://en.unesco.org

[16] Uchoa Branco, A. and Lopes de Oliveira, M.C. (2018) Alterity, Values and Cocialization, Human Development within Educational Contexts. Springer, Cham. https://doi.org/10.1007/978-3-319-70506-4

[17] Bennett, M. and Castiglioni, I. (2004) Embodied Ethnocentrism and the Feeling of Culture. In: Landis, D., Bennett, J. and Bennett, M., Eds., Handbook of Intercultural Training, 3rd Edition, Sage, Thousand Oaks, CA, 249-265. https://doi.org/10.4135/9781452231129.n10

[18] Hall, E.T. (1973) The Silent Language. Anchor Books, New York.

[19] Von Glasersfeld, E. (2003) The Constructivist View of Communication. In: Müller, A. and Müller, K.H., Eds., An Unfinished Revolution, Edition Echoraum, Vienna, 351-360.

[20] Bennett, M.J. (1979) Overcoming the Golden Rule: Sympathy and Empathy. In: Nimmo, D., Ed., Communication Yearbook 3, International Communication Association, Transaction Publishers, New Brunswick, NJ, 406-422. https://doi.org/10.1080/23808985.1979.11923774

[21] Bennett, M. (2013) Overcoming the Golden Rule: Sympathy and Empathy. In: Bennett, M., Ed., Basic Concepts of Intercultural Communication: Paradigms, Principles, \& Practices (Readings), Intercultural Press, Boston, 203-233.

[22] Heine, S.J. (2015) Cultural Psychology. 3rd Edition, W.W. Norton \& Company, New York.

[23] Watzlavick, P., Beavin, J. and Jackson, D.D. (1967) Pragmatics of Human Communication. W.W. Norton \& Company, New York. 
[24] Hofstadter, D. and Dennett (1984) The Mind's I: Fantasies and Reflections on Self and Soul. Bantam, New York.

[25] Adler, N.J. and Gundersen, A. (2008) International Dimensions of Organizational Behavior. 5th Edition, Thomson, Mason.

[26] Moss Kanter, R. (1997) World Class: Thriving Locally in the Global Economy. Touchstone, New York.

[27] Bennett, M. (2013) Basic Concepts of Intercultural Communication: Paradigms, Principles, \& Practices. Intercultural Press, Boston.

[28] Berry, J. (2016) Diversity and Equity. Cross Cultural \& Strategic Management, 23, 413-430. https://doi.org/10.1108/CCSM-03-2016-0085

[29] Berry, J. (2005) Acculturation: Living Successfully in Two Cultures. International Journal of Intercultural Relations, 29, 697-712. https://doi.org/10.1016/j.ijintrel.2005.07.013

[30] Kim, Y.Y. (2001) Becoming Intercultural: An Integrative Theory of Communication and Cross-Cultural Adaptation. Sage, Thousand Oak.

[31] Johnston Conover, P. (2009) The Politics of Recognition: A Social Psychology Perspective. In: Borgida, E., Federico, C.M. and Sullivan, J.L., Eds., The Political Psychology of Democratic Citizenship, Oxford University Press, New York, 176-207. https://doi.org/10.1093/acprof:oso/9780195335453.003.0008

[32] Hooks, B. (2013) Writing Beyond Race: Living Theory and Practice. Routledge, New York.

[33] Yuval-Davis, N. (2006) Intersectionality and Feminist Politics. European Journal of Women's Studies, 13, 193-209. https://doi.org/10.1177/1350506806065752

[34] Buber, M. (1986) I and Thou. 2nd Edition, Scribners, New York.

[35] Perry, W. (1969) Forms of Intellectual and Ethical Development in the College Years. Holt, New York.

[36] Knefelkamp, L. (1999) Introduction. In: Perry, W., Ed., Forms of Intellectual and Ethical Development (Revised Edition), Jossey-Bass, San Francisco.

[37] Kohlberg, L. (1981) Essays on Moral Development, Vol. I: The Philosophy of Moral Development. Harper \& Row, San Francisco, CA.

[38] Gilligan, C. (2008) Moral Orientation and Moral Development. In: Bailey, A. and Cuomo, C.J., Eds., The Feminist Philosophy Reader, McGraw-Hill, Boston.

[39] Adler, N.J. (1980) Cultural Synergy: The Management of Cross-Cultural Organizations. In: Burke, W.W. and Goodstein, L.D., Eds., Trends and Issues in OD. Current Theory and Practice, University Associates, San Diego, 163-184.

[40] Casmir, F. (1993) Third-Culture Building: A Paradigm Shift for International and Intercultural Communication. Annals of the International Communication Association, 16, 407-428. https://doi.org/10.1080/23808985.1993.11678861 